meaning the day of the month. A new bridge was
completed near his residence and the old gentleman completed near his residence and the old gentleman him to "where he had never been before," which indefinite direction was correctly interpreted to mean
the new bridge. This old man had been noted as a linguist, and his aphasic affection took this peculia We may now consider the interesting psychological question. Does the destruction of the vocal power of this point has always been a very difficult question
with the medical profession, because the very nature of
aphasia debars patients from submitting to the regular aphasia debars patients from submitting to the regular tests that doctors apply in cases of suspected insanity
Eminent physicians have differed on the point, as $\mathbf{I}$ will now show. Dr. Trosseau, of France, who origindisease the mind is injured. as the faculty of memory is impaired, and he reaches this conclusion largely of his own, consisting of the showing of certain objects to patients and asking them fanciful nanes for each.
In every case the patient would shake his head, but In every case the patient would shake his head, but
when the doctor mentioned the true name he received aphasia is whether language should be regarded as an outlet for thonght or as an indispensable part of thought
Psychologists claim that thought and language are one, and yet we see that aphasia does not cause the loss of ideas. Persons recovered from aphasia have,
nnfortunately for science, said little upon the point as though thoure their experiences while ill. In 1772 Dr. Spalding, a well-known Berlin physician, was sitting in his study
writing out a receipt for money, and after writing two
words, sudden as a lightning flash he lost all sense of words, sudden as a lightning flash he lost all sense of
their meaning. He tried to write on, but the sense of the words he had intended to write and that of all threw down the pen and tried to speak, but found he he did soon after, Dr. Spalding says that he carried on the thinkiug process, but he has neglected to tell us
whether he thought in words which he could not speak or write. tine, when suddenly the meaning of the words on the printed page completely left.his mind. Much alarmed, tonguetied, whereupon, fearing paralysis, he began to
exercise his limbs, and found them all right. Next he exercise his limbs, and found them all right. Next he
tried to write, but his power to do so was gone. Meantried to write, but his power to do so was gone. Mean-
time he was using all his professional knowledge in an and when a doctor was sumnoned he made signs that he wished to be bled. No sooner was this done than
he recovered, but in leaving a record of his experience
he fails to say how he thought-with or without TYPHOID FEVER IN HARTFURD IN 1891 ANI) 1892

THE last Report of the Stute Bøard of Health of Conneriticut contains a paper on Connecticut River Water as i Source of Ty phoid Fever at Hartford, cont
by Dr. Herbert E. Sinith, the board's chemist.

The water supply of Hartford is ordinarily ample under a gravicy system, feeding a suitable number of ending in 1891, it was at no time necessary to resort to river water, and the pumps at the river stations have
been maintained only for emergencies. In 1891 , however, the storage supply ran so low that a part of the city was supplied from the river, notwithstanding the
fact that it was known that the river was constantly subject to contamination by sewage from Spring-

Hartford. of cases of fever, and Dr. Smith was requested to
inake an investigation in order to learn how far the water supply or other possible sources of the disease
had been at fault. The condition of the river water, it may be said, had been a source of more or less ap water supply, therefore, was properly made the chief milk supply and the ice supply. These latter were severally excluded as the inquiry progressed, and the
river water as a public supply to a part of the city be-
came more and more distinctly incriminated.

The district supplied by river water, being populous and otherwise specially susceptible, had been in predistricts. This peculiarity was present, also, to an exaggerated extent in 1892 , but the greatest significance was attachel to the prevalence of the fever in unusual
months and to the fact that those months corresponded with the period of the river supply plus an average in cination period. Thus there were more cases of ever
during the unusual months, November, December,
and $J$ anuary - a period corresponding to the time when cases originating in the use of the suspected supply
must have appeared. The reporter rejects the argumust have appeared. The reporter rejects the argument as to an epidemic influence possibly existing at
that time, on the score that the fever was manifest nowhere else in the State than in Hartford. marked by a high typhoid fever mortality - the reported
or estimated number of cases not being given for comor estimated number of cases not being given for connparisoll-dine to a return to the use of river water dur-
ing three weeks and a half ending November 18, 1892. This recurrence of fever incst be taken as confirmatory
of the position assumed in respect to the unusual preva-
lence of typhoid ferer a year before-name!y, that the water from the river was a large factor, probably the sent, in fanning the fever flame in winter.
The reporter takes up the question. Why, if the The reporter takes up the question: Why, if the
river water was productive of so many fever cases, river water was productive of so many fever cases,
were there not even more cases? His reply is import ant. He states thaty ure sanitary of the river dis triet to boil the water used for domestic purposes
Furthermore, the river was not grossly polluted at the
time of its examination by Dr. Smith, and was probaas a public source worse at the times when it was used ge, no doubt, flows into the stream, but the dilution
is so very great that the chemical constitution of the water as a whole is not decidedly affected. Although in
the latter part of 1891 the contamination was relatively the latter part of 1891 the contamination was relatively much greater than usual, on account of the low state
of the river, still it is not clear that the water contained servers hould the opinion that under conditions such as
suled at Hartford a lare proportion of the endangered population will resist the contamination, and that only The source of the typhoid fever germs was not
There suscertible

The source of the typhoid fever germs was not pos
ively discovered, but the opinion of the reporter is that miles distant from the point where the Hartford sup ply is taken in. Cases and deaths had occurred at doubted that fever germs entered the river and wer carried south ward. But the investigation was pro-
posed to Dr. Smith at a period when it was too late for him to satisfy himself that the germs of typhoid fever in number and virulence adequate to cause the trans plantation of the disease from the one city to the other.
It is Dr. Smith's belief that this was the manner o aupplion of the winter cases at Hartford in the river-
Dr. Smith feels warranted by his facts in asserting Dr. Smith feels warranted by his facts in asserting
hat the Connecticut River just above Hartford is as pure as at any other point in his State, and he re-
marks that it is unsafe to use its water for drinking at any point in that State. That city is the only one that
has hitherto resorted to river water as a public supply, even in emergencies, and the lesson tanght by the xperiences of the past two years will doubtless pre
vent the repetition of the experiment at any point with in the reach of the influence of the State Board of
Health, of which Dr. Smith is a member. $-N$. Y. Med.

A MUTE WHO IS CAPABLE OF SPEAKING.

As well known, mutes exchange their thoughts by
igns, each corresponding to a letter of the alphabet,

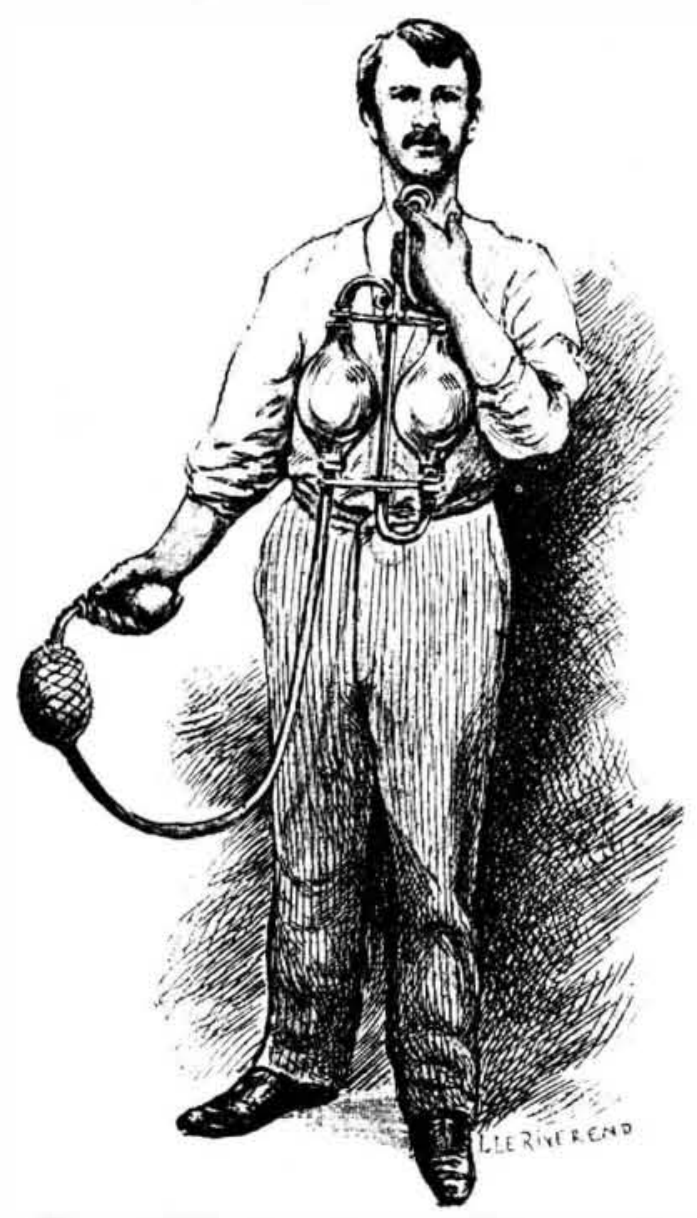

APPARATUS FOR REPLACING A LOS'T LARYNX.

gestures, by a minicry that brings into play the ascles of the face, and even by more or less guttural sounds that translate their agreeable sensations or
their painful impressions. All this, doubtless, constitutes an expressive language, but not a language language. It would seem a priori that when a mute speaks he ceases to be a mute by the very fact
that he modulates his sounds; but such is not always the case. At one of the recent sessions of the Academy of Medicine, Dr. Perier, surgeon of the
Lariboisiere Hospital, presented for the examination
of his colleagues a nlute who expressed all his ideas by speech, that is to say, by modulated sounds. The history of this man is most curious and interest ually enjoying robust health when he was stricken
with an incurable affection of the larynx, the first symptoms of which were observed in January, 1891
Tired of the treatment that he had to undergo fo Tired of the treatment that he had to undergo for
two years, he expressed a desire to be operated upon as radically as possible. ceeded on the 12th of last June to operate upon him for the total extirpation of the larynx. Everv one
knows that the region of the larynx contains the very organ of the voice, and that the vocal apparatus of most perfect of that of the higher beings. Its destruction through disease or accident is consequently
The operation once terminated according to th rules of art, the skillful surgeon formed in the ante--
rior wall of the neck a small orifice which he left This opening, consequently communicating with both the exterior and the pharynx, was reserved for by means of an artificial larynx. Convalescence prothe patient was sufficiently re-established to permit of
the

In concert with Mr. Aubry, the well known manuthese tentatives (for several technical reasons too lon to set forth here) toward the adaptation of an arti-
ficial larynx actuated by a blowing device, and not by the air issuing from the trachea. The apparatus, relatively simple, that they de a tube, and the plates of which, arranged in contrary directions, obliterate half of the light at each $\epsilon x t r e m i t y$. This tube terminates above in a spherical surface capable of being applied hermetically to the orifice in the tic reservoirs, coupled and mounted upon a metallic with the other in order to obtain a continuous curOne of the reservoirs is put in communication with a blowing device formed of a bulb similar to those that actuate vaporizers. Under the effect of the curand emits a constant note of uniform tonality, which The sound thus produced is led, so to speak, into the It remains then, in order to convert it into true soken language, only to make it undergo, through the intermedium of the tongue, lips and teeth, as in
ordinary phonation, the series of modulations that produce the nuances and the difference in the proThese nuances, as incredible as the fact may seem.
at first sight, are, it appears, obtained quite easily. The individual who was suffices.
The object of the conmuication made to the Paris Academy of Medicine was receiving his operator with emotion, to retrace the . a voice that was distinct, although of a
otonous tone.-Le Magasin Pittoresque.

The ADVANTAges OF A scientific EDUCATION.*

By Francis A. Walker, Ll.D

I PRESENT the heartiest congratulations of the Massachusetts institute of Technology to the officers Dr. Bovey, on the fortunate completion and the presthese commodious and superbly equipped laboratorie of physics and engineering. The distinguished position which this university has long held in science and the applications of science to useful arts cannot fail to be greatly advanced as the result of these noble benefac
tions of $\mathrm{Mr}$. McDonald. The growth of scientific and technical schools on ed of the marvelous. In part, it has been due to the American people ; in part, to the recognized need of greater skill and more of scientific knowledge for the development of the natural resources of the continent and for the direction of its growing enterprises. In
this movement of the age, even the older institutions have been compelled profoundly to modify their
traditional courses of study, substituting scientific and even technical instruction for much that was formerly deemed essential to a liberal education Of the reluctance, and even resistance, which this movement has encountered from many who deservedly
held high places in the old educational order, I would work was something essentially less fine and high and noble than the pursuit of rhetoric and philosophy, the leading educators of America a generation ago. And it has not even yet wholly yielded to the demon-
stration offered by the admirable effects of the new education in training young men to be as modest appreciative. as were the best products of the classical culture, and withal, more exact and resolute and
strong. We can hardly bope to see that inveterate prepossession altogether disappear from the uninds of hose who have entertained it. Probabls these gond
men will have to be buried with more or less of their men will have to be buried with more or less of their
prejudices still wrapped about them; but from the new generation scientific and technical studies will disparagement.

Another objection which the new education has en-
. This has arisen from to far more of consideration. This has arisen from the sincere conviction of many are bronght strongly out, loses much of that disinterestedness which they claim, and rightly claim, is of the very essence of education. For the spirit of this objecthese honorable gentlemen in believing that the contemplated uses of science, whether in advancing the usefulness. success, and pecuniary profit of the student of a technical profession, do not neessarily impair that
disinterestedness which I fully coneede is essential to the highest and truest elucation of the man. These necessary fear of the usefulness of science, They Macaulay, in his famous essay on Bacor, doubtless with something of exaggeration, as his custom was, at I am willing to admit that, in my humble judgment, * Remarks on the dedication of the new science and engineering build
ings of McGill University, Montreal, February 24, 1899.-Tech. Quarterily. 
many technical schools have erred in addressing themselves too closely to the practical side of instruction the study of science, and have borne an undue weight upon mere knacks ind labor-saving devices and have made a mistake, even from their own point of view, and with reference to the very objects they pro-
fess. Moreover, 1 an free to acknowledge that those who direct many technical schools have made a mistake, in altogether, or nearly so, onitting from thei tific, liberal as distinguished from exact, studies. Those technical schools will best accomplish their purpose of usefulness, alike to their students and to the State,
which make more of the sciences than of the arts Itore of principles than of their applications, and
which offer to their pupils. in addition to the studies which will make thenl exact and strong, some of the studies and exercises which will help to render them, at the same time, broad and fine. scientific studies as is for the ultimate advantage of
the technical professions themselves, and with such the technical professions themselves, and with such as has been indicated. I believe that the work of the be termed disinterested as that of a student in a classical college. In neither class of institutions can suceess in life and his professional and social position are largely to depend upon the manner in which his
work shall be done in college. All that can be asked in regard to any school is that there shall be zeal in is discerned, high aims, and ambitions which have not strong desire to become a useful man, well equipped for life, capable of doing good work, respected and estedness, in any sense of that word in which an educator would be justified in using it with commend

The practical uselessness for any immediate purpose of a given subject of study may be no reason why it high immediate usefulness of a subject of study furnishes no ground from which the educator of lof tiest or and purest ideals should regard it with contempt is in what spirit the study is pursuod. The most distinguished French writer of to-day on matters of education, writing, too, in advocacy not of physical but of social science, has frankly paid his tribute to
the disinterestedness of spirit and loftiness of motive the disinterestedness of spirit and lof tiness of motive which promote and direct scientific research, even in "pass in revietors of industry, the Keplers and the Fultons, and we shall be struck by the idealistic and evell Utopian tendeney peculiar to them. They are,
in their own way, dreamers, artists, poets, controlled by experience."
And if, leaving abstract reasoning, we turn to con. tellplate the man abe community, I seem to find corare practiced in the community, I seem to find corapplications to the arts of life do not tend to produce
sordid character or to confine the mall merely to sordid character or to confine the mall merely to
material ains. Every profession has its black sheep ind its doubtful practitioners; but, while frankly admitting that there are mercenary physicists and chebetween the scientific men of America, as a body, and its literary men or even its artists, in the respects of
devotion to truth, of simple confidence in the right of devotion to truth, of simple confidence in the right, of
delight in good work for good work's sake, of indisdelight in good work for good work's sake, of indis-
position to coin name and fame into money, of un position to coin name and fame into money, of un-
willingness to use one thing that is well done as a means of passing off upon the public three or four
things that are ill done. I know the scientific men of America well, and I entertain a profound con viction
that in sincerity, simplicity, fidelity, and generosity of
character, in nobility of aims and earnestness of effort, character, in nobility of aims and earnestness of effort,
in everything which should be involved in the conception of disinterestedness, they are surpassed, if in-
leed they are approached, by no other body of men. Let us, then, cheer on every enterprise for the extension of scientific and technical education, without any misgivings as to its effects upon the character and subfear that they will be rendered sordid in spirit or low in their aims by reason of the practical usefulness of
the studies to which they are called to apply themselves. There is a wonderful virtue in the exact sciences to
make their students loyal, just-minded, clear-headed, and strong against temptation. Here, no insidious tendencies to mere plausibility, to sophistry, and to
self-delusion beset the young and the ambitious. The only success here is to be right. The only failure pos-
sible is to be wrong. To be brilliant in error here is only to make the fact of error more conspicuous and than the whole truth, this is the dominating spirit of the laboratory, which never withdraws its control over the student to keep him from the false path, which
never intermits its inspiration as it urges him onward to the light.

THE TRANSPARENCY OF EBONITE TO LIGHT AND HEAT.

SI NOR RICCARDO ARNo has communicated to the
Turin Academy of Sciences certain results obtained by him in the course of an investigation on the action of heat rays of various lengths upon thin plates of
ebonite. He used six different sources of light, the ebonite. He used six different sources of light, the
radiations from which were sent through plates of
ebonite of thicknesses varying from 0.12 to 0.52 millimeter. The thinnest plates absorbed 25 per cent. of the heat radiated from an incandescent lamp. the
lutuinous heat rays of which were cut off by a thick plate of glass. When the source of light was very
bright, this ebonite film was found to transmit a small bright, this ebonite film was found to transmit a small
portion of the visible red rays. The thinnest film portion of the visible red rays. The thinnest film
absorbed 69 per cent. of the dark rays from the
smoked surface of a Leslie cube containing boiling water, while the thicker plates absorbed 88 per cent.

rent for dark rays of heat of low refrangibility than their extremity are observed little ornaments resemor those more nearly approaching the visible spec- bling those of the nit of the louse.
rum. The greatest transparency was shown in re. The eggs of the gulat resemble a skittle, the large spect of the dark heat rays on the border of the end of which is rounded and the other extremity terluminous spectrum. The successive substitution of
a hot iron plate, a glowing platinum wire, a Locatellis
(Fig. 11). (gas) lamp, and an incandescent electric lamp for the
Teslie cube, was followed by a steady increase of the ephemerre are almost imperceptible.

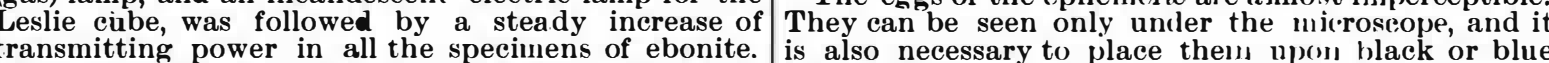
These observations may be studied in connection with
Th also neessary to place them upon black or blu
paper. They are plano-ronvex and oblong in form. Tesla's experiments with high frequency phenomena,
which go to indicate that the transparency of media
nebulous under the microscope. They are white, a which go to indicate that the transely a question of conditions.

\section{THE EGGS OF INSECTS.}

Swammerdam, a Duteh scientist, who was the first to examine insects under the microscope, and whose
researches were published in 1737 , through the care of the illustrious Boerhaave, has given some curious de"Some are oblong," says he, "while others are ovoi or round. There are angular, pyranidal, striate and
granular ones. There is no less variety as regards colgranular ones. There is no less variety as regards col-
ors; we find white, yellow, red, blue and green ones, and others variegated with colors so singularly conactly.
"As for consistence, some are soft and others hard. There are some that are membranous, and others that the shell of a hen's egg. Finally, certain of them ar
covered with a sơrt of froth, while others are covered with hairs." a sort of froth, while others are covered
Swammerdam has described with much detail the ggs of the Nepea cinerea, a small fresh water hem-
pter, which he calls the "water scorpion" (Fig. 10). They are of a yellow color, and nearly of the same is also the internal tunic of their shell.
If the eggs of the ephemerze are minute, those of the Euryantes horribilis, a New Guinea orthopter, are, on
the contrary, as large, it is said, as the eggs of the the contrary, as large, it is said, as the eggs of th
humming bird. The privy fly has an oblong, angular egg with work. They are very white, and are composed of two distinct envelopes, the external one of which is a true distinct
shell lik.
easily.

The egg of the ant is plain, smooth and lustrous, without any division. After the larva has made its which has curled up and become reduce hatched it is still so small as to escape the eyes. This is what makes these eggs so little known, for what is commonly and very improperly called the egg of the ant is the latter's larva endowed with life and motion.
These eggs, or rather these larva, are much in demand as food for poultry.

The eggs of ants are considered a choice dish in some butter, and sauces are made of them that are considvided at the upper part with seven slender branches portant trade in some countries of the north of Eu-

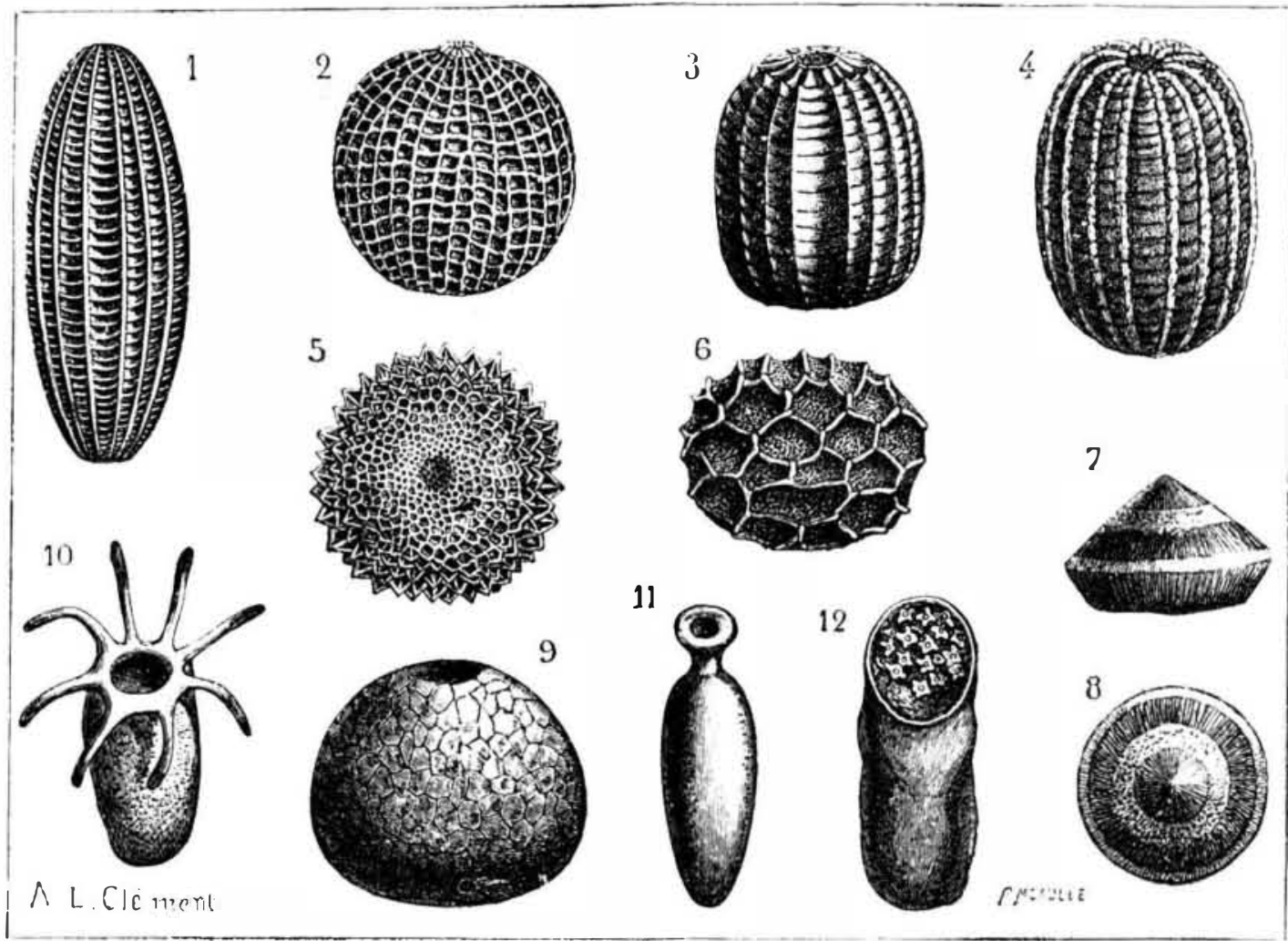

INSECTS' EGGS.

and 2. eggs of the large and small cabbage butterfly ; 3 , egg of Papillo hyperantus; 4 , egg of Vanessa ata. lanta; 5 and 6 , eggs of Polyommates; 7 and 8 , egg of Dicranura vinula (front and side view); 9 , egg of
Pygcera tucephola; 10 , egg of Nepea cinerea ; 11, egg of gnat; 12 , nit of louse.

or stiff brist

These appendages, arranged circularly upon the circumference of each egg, form a sort of open-work egg-
cup, which receives in its cavity the end of the followng egg, so that the appendages of the first egg em-
eng brace the lower extremity of the second, those of the
second embrace the third, and so on throughout the

The eggs of the lepidopters have much analogy
with the seeds of plants (Figs. 1, 2, 3 and 4). Those of the suall and large cabbage moth have the form of a pyramid, whose base is fastened to a leaf, and the
height of which is three or four times greater than the diameter of its base. The eggs are ordinarily formed of eight rounded ribs separated by as many grooves,
which extend from the summit to the base. Upon each of these ribs is observed an infinite number of grooves parallel with the base. Those of the large tortoise
butterfly are spherical. They are stualler in diameter
at the base, or part by which they adhere to the plant. at the base, or part by which they adhere to the plant,
than at the summit, where there are eight equally than at the summit, where there are eight equally
spaced ridges that descend along the body of the egg, here they form ribs that diminish insensibly in height These eggs bear quite a resemblance to those of a designate by its specific name, and which attaches its
ogs in circular rows to branches of trees, to which eggs in circular rows to branches of trees, to which
they adhere so firmly that they leave an imprint upon the bark and even interfere with the nutrition of the ranch to which they are glued. These eggs are also hat are cut for the construction of vaults, and which are wider at the summit than at the base, so that in Other lepidopters have eggs of a very elegant form. They resemble a sort of small knot channeled and s The eggs of the dragon flies are elongated, and at rope, principally in Denmark, Norway and $S$ weden in these countries they are cooked in boiling water In Mexico, the eggs of certain aquatic hemipters are eaten. These insects (Corixa femorale, mipters are and Notonecta Americana) habitually deposit thei eggs among the reeds and sedges of the lakes, prin
cipally of Lake Tescuco. These reeds and sedges ar gathered and dried and beaten over cloths in order to detach the myriads of eggs that are attached to them. These egge are cleand with the greatest care, and are
afterward sifted and put into bags like flour and sold for making bread.

This new kind of food, called hantli, and which, upon the whole, is merely bread made from an aquatic bug markets The aborigines, before the in the use of this bread, which has a pronounced taste of fish The eggs of another species, Coriac esculenta, which ments of very choice dishes.

Let us add, in conclusion, that the eggs of insects withstand great variations of temperature. The most

the eggs of the most delicate speries, and just so they resist a tropical heat that would suffice to roast meat

THE ORIGIN OF GOLD.

By Philip Lake, Cambridge, England.

THE subject of the origin of gold, or of the manner in which that metal has reached its present positions, is tion, and the number of theories put forward has been question. It is easy to understand the presence of gold in alluial deposits, for this has clearly been derived aron 